\title{
Hubungan Pemasaran Rumah Sakit (Marketing Mix 7P) terhadap Tingkat Kunjungan Pasien
}

\author{
Puji Lestari ${ }^{1}$, Rindu ${ }^{2}$ \\ ${ }^{1}$ Puskesmas Kecamatan Tebet, J In. Tebet Timur II No.2 RT.10/RW.05, Tebet Timur-J akarta Selatan \\ 12820, Telp: (021) 8350632 \\ ${ }^{2}$ Program Studi Sarjana IImu Kesehatan Masyarakat, Sekolah Tinggi IImu Kesehatan Indonesia Maju \\ J In. Harapan Nomor 50, Lenteng Agung-J akarta Selatan 12610, Telp: (021) 78894045 \\ Email: ${ }^{1}$ pujilestarikedua@gmail.com, ${ }^{2}$ rindualghie@gmail.com
}

\begin{abstract}
Abstrak
Seiring berkembangnya jaman mengakibatkan persaingan bisnis yang semakin ketat termasuk dalam perumahsakitan. Oleh karna itu dibutuhkan pemasaran rumah sakit untuk mempromosikan dan mengelola rumah sakit agar tetap maju dan berkembang. Tujuan umum penelitian ini untuk mengetahui hubungan pemasaran rumah sakit dengan tingkat kunjungan pasien di Rumah Sakit Sahid Sahirman tahun 2017. Metode penelitian deskriptif kuantitatif. Penelitian ini dilakukan pada bulan Januari 2018 di RS Sahid Sahirman. Populasi penelitian ini adalah seluruh pasien rawat inap RS Sahid Sahirman selama periode penelitian. Sampel penelitian diambil secara purposive sampling ini berjumlah 37 pasien rawat inap Rumah Sakit Sahid Sahirman. Hasil penelitian menunjukkan bahwa ada hubungan pemasaran rumah sakit terhadap tingkat kunjungan pasien di RS Sahid Sahirman Tahun 2017, dimana uji chi-square di dapat hasil Product $(P$-value $=0,000)$, Promotion $(P$-value $=0,000)$, Place $(P$-value $=0,00 I)$, People $(P$-value $=$ $0,000)$, Process $(P$-value $=0,000)$, dan Physical Evidence $(P$-value $=0,000)$, lebih kecil dari $0,05(<0,05)$ sehingga ada hubungan dengan tingkat kunjungan. Sedangkan Price $(P$-value $=0,072)$, lebih besar dari $0,05(>0,05)$ tidak ada hubungan dengan tingkat kunjungan.. Di sarankan bagi manajemen RS Sahid Sahirman untuk meningkatkan meningkatkan kualitas bauran pemasarannya, dan bagi pasien agar mendapat layanan jasa yang berkualitas, dalam memilih RS untuk berobat agar melakukan evaluasi terhadap tarif, profesionalitas SDM, kecepatan layanan dan kualitas fisik dan peralatan Rumah Sakit tersebut.
\end{abstract}

Kata kunci : Pemasaran RS, Marketing Mix, Tingkat Kunjungan.

\section{Abstract}

As the development of the era resulted in increasingly fierce business competition including in hospitals. That's why it takes hospital marketing to promote and manage the hospital to stay ahead and grow. General purpose of this research is to know relationship of hospital marketing with patient visit level at Sahid Sahirman Hospital year 2017. Quantitative descriptive research method. This research was conducted in January 2018 at Sahid Sahirman Hospital. The population of this study as much as all inpatients RS Sahid Sahirman on research. Research sample taken by random sampling is amount of 37 hospitalization patient Sahid Sahirman Hospital. The results showed that there was a relationship of hospital marketing to the level of patient visit at Sahid Sahirman Hospital in 2017, where chi-square test result can be Product ( $X=$ $0,000)$, Promotion $(X=0,000)$, Place $(X=0.001)$, People $(X=0,000)$, Process $(X=0,000)$, and Physical Evidence $(X=$ $0,000)$, less than $0.05(<0.05)$ so that there is a relation with visit level. Whereas Price $(X=0.072)$, greater than $0.05(>$ 0.05 ) is not related to visitation rates. It is recommended for Sahid Sahirman Hospital management to improve the quality of the marketing mix, and for patients to obtain qualified, in choosing hospitals for treatment in order to evaluate the tariff, professionalism of human resources, speed of service and physical quality and equipment of the Hospital

Keywords : Hospital Marketing, Marketing Mix, Visit Rate 


\section{Pendahuluan}

Undang-undang Republik Indonesia Nomor 36 Tahun 2009 tentang Kesehatan menyatakan tujuan pembangunan kesehatan adalah tercapainya kemampuan hidup sehat bagi setiap penduduk, untuk mewujudkan derajat kesehatan yang optimal sebagai investasi bagi pembangunan sumber daya manusia yang produktif secara sosial dan ekonomis. Untuk mencapai tujuan tersebut diselenggarakan upaya kesehatan yang menyeluruh, terpadu, merata dan dapat diterima serta terjangkau oleh seluruh lapisan masyarakat, dengan peran serta masyarakat sebagai salah satu faktor yang memberikan andil bagi keberhasilan pembangunan kesehatan untuk meningkatkan pengetahuan, kesadaran dan perilaku masyarakat di bidang kesehatan. ${ }^{1}$

Rumah sakit adalah sarana kesehatan yang menyelenggarakan pelayanan kesehatan secara merata, dengan mengutamakan upaya penyembuhan penyakit dan pemulihan kesehatan, yang dilaksanakan secara serasi dan terpadu dengan upaya penigkatan kesehatan dan pencegahan penyakit dalam suatu tatanan rujukan, serta dapat dimanfaatkan untuk pendidikan tenaga penelitian. ${ }^{2}$ Sedangkan Undang-Undang Nomor 44 Tahun 2009 tentang rumah sakit menyebutkan bahwa rumah sakit adalah institusi pelayanan kesehatan yang menyelenggarakan pelayanan kesehatan perorangan secara paripurna (meliputi promotif, preventif, kuratif, dan rehabilitatif) dengan menyediakan pelayanan rawat inap, rawat jalan, dan gawat darurat. ${ }^{3}$

Profil Kesehatan Indonesia tahun 2016 menyatakan jumlah Rumah sakit di Indonesia dari tahun 2013-2016 mengalami peningkatan. Pada tahun 2013 jumlah rumah sakit sebanyak 2228 meningkat menjadi 2.601 tahun 2016. Jumlah rumah sakit di Indonesia sampai dengan tahun 2016 terdiri dari 2.046 Rumah Sakit Umum (RSU) dan 555 Rumah Sakit Khusus (RSK). Jelas bahwa rumah sakit-rumah sakit di Indoesia mengalami persaingan yang ketat, oleh sebab itu, tidak keliru jika pengelola rumah sakit mulai melirik pemasaran dengan harapan dapat menjawab tantangantantagan yang ada. ${ }^{4}$

Pemasaran adalah proses sosial dimana individu-individu dan kelompokkelompok dalam masyarakat berupaya untuk memenuhi kebutuhan dan mendapatkan apa yang diinginkannya melalui penciptaan, penawaran, dan tukarmenukar barang dan jasa secara bebas. ${ }^{5}$ Sedangkan pendapat lain mengenai pemasaran adalah upaya untuk menyinergikan sejumlah kegiatan, yaitu perancangan pelayanan, penetapan tarif/harga, komunikasi atau promosi, dan peyediaan tempat untuk penyelenggaraan pelayanan, dalam suatu perangkat yang disebut bauran pemasaran (marketing mix). ${ }^{2}$

Pemasaran terdiri dari tindakantindakan yang menyebabkan berpindahnya hak milik atas barang serta jasa dan yang menimbulkan distribusi fisik mereka. Proses pemasaran ini meliputi aspek fisik dan nonfisik, yang menyangkut perpindahan barang-barang ke tempat di mana mereka dibutuhkan merupakan aspek fisik, sedangkan aspek nonfisiknya yaitu para penjual harus mengetahui apa yang diinginkan oleh para pembeli dan pembeli harus pula mengetahui apa yang dijual. ${ }^{6}$

Marketing Mix adalah campuran dari variabel-variabel pemasaran yang dapat digunakan oleh suatu perusahaan untuk mengejar tingkat penjualan yang diiginkan dalam pasar sasaran. ${ }^{7}$ Strategi bauran pemasaran dianggap sebagai salah satu konsep inti teori pemasaran. Konsep bauran pemasaran tradisional terdiri dari 4P yaitu product, price, place, promotion. Sementara itu untuk pemasaran jasa perlu bauran pemasaran yang diperluas dengan penambahan non tradisional bauran pemasaran yaitu people, physcal evidance, dan process, sehingga menjadi 7 unsur (7P). Masing-masing dari tujuh unsur bauran pemasaran tersebut saling berhubungan dan bergantung satu sama 
lainnya dan mempunyai suatu bauran yang optimal sesuai dengan karakteristik segmennya. ${ }^{8}$

Dalam teori ekonomi neoklasik, diasumsikan bahwa setiap orang yang akan mengonsumsi suatu produk jasa, memiliki pengetahuan atau informasi yang cukup tentang produk jasa tersebut dan berada dalam posisi yang tepat. Dengan demikian, orang akan menganggap suatu produk/jasa bernilai bagi dirinya, jika produk/jasa itu memiliki kegunaan atau manfaat baginya. Dalam keadaan seperti ini konsumen dianggap memiliki kedaulatan penuh. Upaya pemasaran rumah sakit akan membuat konsumen memiliki pengetahuan atau informasi yang cukup tentang pelayanan rumah sakit. Maka jika upaya pemasaran dapat dilaksanakan dengan baik oleh rumah sakit, hubungan keagenan antara pemberi pelayanan dengan klien/pasien tidak lagi disalahgunakan. ${ }^{2}$

Bauran pemasaran merupakan salah satu strategi pemasaran untuk menyampaikan informasi secara luas, memperkenalkan suatu produk barang dan jasa, merangsang konsumen untuk memberi bahkan menciptakan preferensi pribadi terhadap image suatu produk. Upaya-upaya untuk memuaskan kebutuhan konsumen dilakukan oleh setiap perusahaan dengan berbagai strategi dan cara dengan harapan konsumen merasa puas dan akan melakukan pembelian ulang. Apabila seorang konsumen telah berubah menjadi pelanggan yang loyal karena kepuasannya terpenuhi, maka konsumen tersebut tidak akan beralih ke produk atau jasa perusahaan lain yang sejenis. $^{9}$

Untuk memenuhi harapan pelanggan, manajemen harus mampu mengeksplorasi harapan dan menyediakan atau mewujudkan dalam bentuk pelayanan yang dapat dirasakan secara langsung maupun tidak langsung. Hasil penelitian sebelumnya yang dilakukan oleh Hardianti mengenai Hubungan Bauran Pemasaran dengan Loyalitas Pasien di Unit Rawat Inap RS. Grha Permata Ibu pada tahun
2016, menunjukkan bahwa ada hubungan antara Bauran Pemasaran dengan loyalitas pasien di RS. Namun, belum ada pola khusus dalam pemasaran, sehingga proses pelaksanaannya masih mengacu pada promosi. ${ }^{11}$

Sebagian besar marketing yang dilakukan di Rumah Sakit Sahid Sahirman adalah membuat progam workshop dan sosialisasi seminar. Saat ini RS Sahid Sahirman tidak hanya menyasar pasien ekonomi menengah ke atas tapi juga sudah kearah pasien ekonomi bawah dengan bekerjasama dengan BPJS kesehatan. Permasalahan yang terjadi adalah tingkat kujungan pasien yang masih cukup sedikit untuk ukuran Rumah Sakit Tipe B. Persaingan ini terjadi tidak hanya dari sisi teknologi pemeriksaan, akan tetapi persaingan yang lebih berat yaitu dalam pelayanan kesehatan yang berkualitas. Proses keputusan pembelian melalui beberapa tahapan dimulai dari pengenalan kebutuhan, pencarian informasi, evaluasi alternatif hingga menghasilkan pada keputusan pembelian yang menentukan prilaku pasca pembelian. ${ }^{12}$

Selama kurang lebih 9 tahun Rumah Sakit Sahid Sahirman berdiri, sempat terjadi peningkatan yang pesat dalam jumlah kunjungan pasien. Namun seiring berjalannya persaingan bisnis di bidang kesehatan, terjadi penurunan jumlah kunjungan pasien pada 3 tahun terakhir terutama pada era BPJS Kesehatan. Rumah Sakit ini baru bergabung dengan BPJS Kesehatan pada 2016, dan belum diterapkan pada semua poliklinik yang ada. Dari pengambilan data awal di Rumah Sakit Sahid Sahirman diperoleh gambaran mengenai tingkat kunjungan pasien rawat jalan dan rawat inap Rumah Sakit Sahid Sahirman 5 tahun terakhir. ${ }^{13}$

Berdasarkan latar belakang tersebut, maka dilakukan penelitian dengan tujuan dari adalah untuk mengetahui hubungan antara pemasaran (marketing mix 7P) rumah sakit terhadap tingkat kunjungan pasien di Rumah Sakit Sahid Sahirman tahun 2017. 


\section{Metode}

Penelitian ini adalah kuantitatif deskriptif dengan desain cross sectional yang bertujuan untuk menganalisis hubungan antara variabel independen (Product, Price, Place, Promotion, People, Physycal evidence, Procces) dan variabel dependen (Tingkat Kunjungan di Rumah Sakit Sahid Sahirman) melalui pengujian hipotesa yaitu untuk menganalisis Hubungan pemasaran rumah sakit dengan tingkat kunjungan pasien di Rumah Sakit Sahid Sahirman Tahun 2017 (Marketing Mix).

Data yang diteliti diperoleh dari data sekunder yang diperoleh dari laporan interen rumah sakit, pengamatan langsung jumlah pasien yang berkunjung selama periode penelitian, serta data primer yang didapatkan dari pasien yang bersedia mengisi kuesioner.

Populasi dalam penelitian ini adalah seluruh pasien di Rumah Sakit Sahid Sahirman, terutama pasien rawat inap yang selama periode penelitian (Juli - Agustus) berjumlah 146 pasien rawat inap. Besar sampel yang digunakan dalam penelitian ini adalah berdasarkan rumus untuk desain penelitian cross sectional, yaitu sebanyak 37 responden.

Kriteria inklusi dan ekslusi dalam penelitian ini adalah (1) Pasien yang bersedia menjadi responden, dapat membaca dan menulis, berada ditempat saat kuesioner dibagikan dan dalam kondisi stabil/masa penyembuhan. (2) kriteria ekslusi yaitu pasien tidak bersedia menjadi responden, dalam kondisi tidak sadar atau tidak berada di tempat saat pengambilan data sampling.

Validitas adalah suatu indeks yang menunjukkan bahwa instrumen yang dipakai benar-benar mengukur apa yang hendak diukur. Kuesioner telah memiliki validitas, berarti semua item yang ada di dalam kuesioner tersebut mampu mengukur konsep yang diukur. Jika nilai $r_{\text {hitung }}$ lebih besar dari $r_{\text {tabel }}$ maka item tersebut valid, sebaliknya jika nilai $\mathrm{r}_{\text {hitung }}$ lebih kecil dari $\mathrm{r}_{\text {tabel }}$ maka item tersebut tidak valid. ${ }^{14}$ Dalam penelitian ini peneliti hanya melakukan uji validitas pada variabel product, price, promotion, place, people, procces, physical evidence.

Reliabilitas adalah indeks yang menunjukkan kehandalan atau dapat dipercaya dari suatu alat ukur. Kuesioner telah memiliki reliabilitas, berarti semua item yang ada di dalam kuesioner tersebut hasil pengukurannya tetap konsisten atau tetap asas, apabila dilakukan pengukuran berulang kali terhadap gejala yang sama dan menggunakan alat ukur yang sama.Uji validitas dan reliabilitas di olah menggunakan program SPSS Statistics 23. Hasil uji validitas dan reliabilitas didapatkan semua daftar pernyataan pada variabel product, price, promotion, place, people, procces, physical evidence.

Metode analisis data yang digunakan dalam penelitian ini adalah analisis univariat dan bivariat. Analisis univariat yaitu langkah mengekplorasi data dari suatu variabel, biasanya dilakukan untuk meringkas data menjadi ukuran tertentu. Analisis bivariat yaitu dilakukan untuk mengetahui hubungan antara variabel independen dan variabel dependen.

\section{Hasil Penelitian \\ Uji Univariat dan Bivariat}

Analisis univariat bertujuan untuk menjelaskan karakteristik setiap variabel penelitian. Hasil analisis univariat di jelaskan pada Tabel 1 dan 2 .

Distribusi frekuensi karateristik responden, berdasarkan hasil penelitian pada Tabel 2 dibawah, di ketahui bahwa dari 37 responden, mayoritas pasien di Rumah Sakit Sahid Sahirman berjenis kelamin laki-laki yaitu sebanyak 20 responden (54,06\%), mayoritas berusia 4 50 yaitu sebanyak 17 responden (45,95 \%) dan mayoritas berpendidikan S1 yaitu sebanyak 21 responden (56,76\%).

Dari ke-7 variabel Marketing Mix terdapat 6 variabel yang berhubungan yaitu Product, Promotion, Place, People, Procces, dan Physical Evidence. Dimana variable tersebut tidak mempengaruhi pemasaran di RS 
Tabel 1. Karakteristik Responden

\begin{tabular}{llcc}
\hline & Kategori & n & \% \\
\hline Jenis Kelamin & Laki-Laki & 20 & 54,06 \\
& Perempuan & 17 & 45,94 \\
Usia (tahun) & $21-30$ & 7 & 18,92 \\
& $31-40$ & 13 & 35,14 \\
Pendidikan & $41-50$ & 17 & 45,95 \\
& SMP & 1 & 2,70 \\
& SMA & 12 & 32,43 \\
& S1 & 21 & 56,76 \\
& S2/S3 & 3 & 8,11 \\
\hline
\end{tabular}

Tabel 2. Analisis Univariat

\begin{tabular}{llcc}
\hline Variabel & Kategori & n & \% \\
\hline Produk & Kurang Baik & 18 & 48,6 \\
\multirow{2}{*}{ Price } & Baik & 19 & 51,4 \\
& Kurang Baik & 18 & 48,6 \\
Promotion & Baik & 19 & 51,4 \\
& Kurang Baik & 18 & 48,6 \\
Place & Baik & 19 & 51,4 \\
& Kurang Baik & 15 & 40,50 \\
People & Baik & 22 & 59,50 \\
& Kurang Baik & 17 & 45,9 \\
Process & Baik & 20 & 54,1 \\
\multirow{3}{*}{ Physical Ev } & Kurang Baik & 20 & 54,1 \\
& Baik & 17 & 45,9 \\
TingKunjungan & Kurang Baik & 17 & 45,9 \\
& Baik & 20 & 54,1 \\
& Kurang Baik & 20 & 54,1 \\
& Baik & 17 & 45,9 \\
\hline
\end{tabular}

Sahid Sahirman atau dapat dikatakan sudah cukup baik. Sedangkan terdapat 1 variabel yang tidak berhubungan yaitu Price dimana variable ini belum cukup baik dibanding variable yang lain.
Tabel 3, menunjukkan bahwa 16 orang $(43,2 \%)$ responden yang menilai produk baik dan tingkat kunjungan baik dan 17 (45,9\%) responden yang menilai produk kurang baik dan tingkat kunjungan kurang baik. Hasil uji hipotesis chi square diperoleh p-value sebesar 0,000, kurang dari 0,05, maka dapat disimpulkan bahwa ada hubungan variabel produk dengan tingkat kunjungan di RS Sahid Sahirman di tahun 2017.

Sebanyak 6 orang (16,21\%) responden yang menilai price baik dan tingkat kunjungan baik. Sedangkan ada 7 (18,91\%) responden yang menilai price kurang baik dan tingkat kunjungan kurang baik baik. Hasil uji hipotesis chi square diperoleh p-value sebesar $0,072,>0,05$, maka dapat disimpulkan bahwa tidak ada hubungan variabel price dengan tingkat kunjungan di RS Sahid Sahirman di tahun 2017. Sebanyak 16 orang (43,2\%) responden yang menilai promotion baik dan tingkat kunjungan baik. Sedangkan ada 17 (45,9\%) responden yang menilai promotion kurang baik dan tingkat kunjungan kurang baik. Hasil uji hipotesis chi square diperoleh p-value sebesar 0,000, kurang dari 0,05, maka dapat disimpulkan bahwa ada hubungan variabel promotion dengan tingkat kunjungan di RS Sahid Sahirman di tahun 2017.

Tabel 3. Hubungan Marketing Mix dengan Tingkat Kunjungan di Rumah Sakit Sahid Sahirman

\begin{tabular}{|c|c|c|c|c|c|c|c|}
\hline \multirow{3}{*}{ Variabel } & \multirow{3}{*}{ Kategori } & \multicolumn{4}{|c|}{ Tingkat Kunjungan } & \multirow{3}{*}{ P-value } & \multirow{3}{*}{$\begin{array}{c}\text { OR } \\
(95 \% \mathrm{CI})\end{array}$} \\
\hline & & \multicolumn{2}{|c|}{$\begin{array}{c}\text { Kurang } \\
\text { Baik }\end{array}$} & \multicolumn{2}{|c|}{ Baik } & & \\
\hline & & $\mathbf{n}$ & $\%$ & $\mathbf{n}$ & $\%$ & & \\
\hline \multirow[t]{2}{*}{ Produk } & Kurang Baik & 17 & 45,95 & 1 & 2,70 & 0,000 & 90,667 \\
\hline & Baik & 3 & 8,11 & 16 & 43,24 & & \\
\hline \multirow[t]{2}{*}{ Price } & Kurang Baik & 7 & 18,92 & 11 & 29,73 & 0,072 & 0,294 \\
\hline & Baik & 13 & 35,14 & 6 & 16,22 & & \\
\hline \multirow[t]{2}{*}{ Promotion } & Kurang Baik & 17 & 45,95 & 1 & 2,70 & 0,000 & 91,167 \\
\hline & Baik & 3 & 8,11 & 16 & 43,24 & & \\
\hline \multirow[t]{2}{*}{ Place } & Kurang Baik & 3 & 8,11 & 12 & 32,43 & 0,001 & 0,074 \\
\hline & Baik & 17 & 45,95 & 5 & 13,51 & & \\
\hline \multirow[t]{2}{*}{ People } & Kurang Baik & 17 & 45,95 & 0 & 0,00 & $\mathbf{0 , 0 0 0}$ & 1,115 \\
\hline & Baik & 3 & 8,11 & 17 & 45,95 & & \\
\hline \multirow[t]{2}{*}{ Process } & Kurang Baik & 20 & 54,05 & 0 & 0,00 & $\mathbf{0 , 0 0 0}$ & 2,221 \\
\hline & Baik & 0 & 0,00 & 17 & 45,95 & & \\
\hline \multirow[t]{2}{*}{ Physical Ev } & Kurang Baik & 2 & 5,41 & 15 & 40,54 & 0,000 & 0,015 \\
\hline & Baik & 18 & 48,65 & 2 & 5,41 & & \\
\hline
\end{tabular}


Sebanyak 5 orang $(13,51 \%)$ responden yang menilai place baik dan tingkat kunjungan baik. Sedangkan ada 3 $(8,1 \%)$ responden yang menilai place kurang baik dan tingkat kunjungan kurang baik. Hasil uji hipotesis chi square diperoleh p-value sebesar 0,001, lebih kecil dari 0,05, maka dapat disimpulkan bahwa ada hubungan variabel place dengan tingkat kunjungan di RS Sahid Sahirman di tahun 2017 (Tabel 3).

Sebanyak 17 orang (45,9\%) responden yang menilai people baik dan tingkat kunjungan baik, dan 17 (45,9\%) responden menilai people kurang baik dan tingkat kunjungan kurang baik. Hasil uji hipotesis chi square diperoleh p-value sebesar 0,000, kurang dari 0,05, maka dapat disimpulkan bahwa ada hubungan variabel people dengan tingkat kunjungan di RS Sahid Sahirman di tahun 2017 (Tabel 3).

Sebanyak 17 orang (45,9\%) responden yang menilai process baik dan tingkat kunjungan baik. Sedangkan 20 (54\%) responden yang menilai process kurang baik dan tingkat kunjungan kurang baik. Hasil uji hipotesis chi square diperoleh p-value sebesar 0,000, kurang dari 0,05, maka dapat disimpulkan bahwa ada hubungan variabel process dengan tingkat kunjungan di RS Sahid Sahirman di tahun 2017 (Tabel 3).

Sebanyak 2 orang $(5,4 \%)$ responden yang menilai physical evidence baik dan tingkat kunjungan baik. Sedangkan 2 $(5,4 \%)$ responden yang menilai physical evidence baik dan tingkat kunjungan baik. Hasil uji hipotesis chi square diperoleh pvalue sebesar 0,000, kurang dari 0,05, maka dapat disimpulkan bahwa ada hubungan variabel physical evidence dengan tingkat kunjungan di RS Sahid Sahirman di tahun 2017 (Tabel 3).

\section{Pembahasan}

\section{Hubungan Produk Terhadap Tingkat Kunjungan RS Sahid Sahirman}

Berdasarkan hasil penelitian didapat $16(43,2 \%)$ responden yang menilai produk baik dan tingkat kunjungan baik dan 17 (45,9\%) responden yang menilai produk kurang baik dan tingkat kunjungan kurang baik. Hasil uji hipotesis chi square diperoleh p-value sebesar 0,000, kurang dari 0,05, maka dapat disimpulkan bahwa ada hubungan variabel produk dengan tingkat kunjungan di RS Sahid Sahirman di tahun 2017.

Hasil penelitian ini sejalan dengan penelitian yang dilakukan Nurhalimmah dan Sugiarsi Tahun 2008 yang berjudul "Gambaran Tingkat Kepuasan Pasien Rawat Jalan Kunjungan Ulang Di Rumah Sakit PKU Muhammadiyah Karanganyar" yang menyatakan produk jasa Rumah Sakit PKU Muhammadiyah Karanganyar bermutu baik dan berhubungan signifikan dengan kunjungan ulang pasien. ${ }^{15}$

Lebih lanjut, penelitian ini juga sejalan dengan penelitian Retnaningtyasm, dkk Tahun 2016 yang berjudul "Persepsi Pasien terhadap Bauran Pemasaran Rumah Sakit dan Pilihan Rumah Sakit", hasil penelitiannya menunjukkan pasien memiliki persepsi positif pada produk Rumah Sakit, Pasien menyatakan bahwa bauran pemasaran menjadi referensi dalam memilih Rumah Sakit. ${ }^{16}$

Menurut peneliti, kebutuhan perusahaan untuk meningkatkan mutu produk/jasa semakin besar karena perdagangan bebas yang terbuka dalam era globalisasi. Oleh sebab itu, perusahaan di dalam negeri diharapkan mempersiapkan diri untuk membina organisasi terutama sumber daya dan sistem untuk menghadapi kedatangan pesaing industri sejenis dan industri lainnya. Rumah sakit merupakan salah satu perusahaan yang dituntut mampu memenangkan persaingan. Untuk itu, rumah sakit harus mampu menyediakan dan memberikan jasa layanan kesehatan yang bermutu bagi pasien. Pelayanan jasa kesehatan yang bermutu merupakan isu untuk memenangkan persaingan bagi rumah sakit. Selain itu, sebagai upaya rumah sakit untuk menghindari dan mencegah tuntutan masyarakat sesuai dengan Undang-Undang 
No. 8 Tahun 1999 tentang Perlindungan Konsumen. Rumah Sakit Sahid Sahirman telah memiliki produk yang baik dan berhubungan dengan tingkat kunjungan pasien.

\section{Hubungan Price Terhadap Tingkat Kunjungan RS Sahid Sahirman}

Berdasarkan hasil penelitian didapat 6 (16,21\%) responden yang menilai price baik dan tingkat kunjungan baik. Sedangkan ada 7 (18,91\%) responden yang menilai price kurang baik dan tingkat kunjungan kurang baik baik. Hasil uji hipotesis chi square diperoleh p-value sebesar 0,072, lebih dari 0,05, maka dapat disimpulkan bahwa tidak ada hubungan variabel price dengan tingkat kunjungan di RS Sahid Sahirman di tahun 2017.

Hasil penelitian ini sejalan dengan penelitian yang dilakukan oleh Retnaningtyas, dkk Tahun 2016 yang berjudul "Persepsi Pasien terhadap Bauran Pemasaran Rumah Sakit dan Pilihan Rumah Sakit", hasil penelitiannya menunjukkan pasien RS Syuhada Haji memiliki persepsi positif pada kesesuaian harga dengan layanan yang diberikan Rumah Sakit, dengan kata lain Rumah Sakit Syuhada Haji memberikan penawaran harga sesuai kualitas. ${ }^{16}$

Lebih lanjut, penelitian ini juga sejalan dengan penelitian Rifai dan Susanto Tahun 2016 yang berjudul "Pengaruh Kualitas Pelayanan dan Bauran Pemasaran terhadap Kepuasan Pasien Rumah Sakit". hasil penelitiannya menunjukkan Pasien RSUD Wirosaban dalam penelitian menilai bauran pemasaran, salah satunya price (harga) terbuktinya berpengaruh terhadap kepuasan pasien dan akan membuat tingkat kunjungan meningkat. ${ }^{17}$

Harga merupakan sejumlah uang yang dibebankan atas suatu produk atau jasa, atau jumlah dari nilai yang ditukarkan konsumen atas manfaat-manfaat karena memiliki atau menggunakan produk atau jasa tersebut. Menurut peneliti, berkembangnya jumlah rumah sakit di
Jakarta menjadikan masyarakat Jakarta memiliki banyak pilihan untuk menentukan rumah sakit mana yang akan mereka pilih. Masyarakat akan memilih rumah sakit yang mereka pandang memberikan kesesuaian harga (Price) dengan layanan yang diberikannya. Oleh karenanya diharapkan Rumah Sakit Sahid Sahirman hendaknya berorientasi pada kualitas layanan untuk dapat bersaing dengan rumah sakit lain. Jika harga (Price) sesuai dengan kualitas layanan maka pasien akan memilih RS Sahid Sahirman yang pada akhirnya terlihat pada tingkat kunjungan yang tinggi.

\section{Hubungan Promotion Terhadap Tingkat Kunjungan RS Sahid Sahirman}

Berdasarkan hasil penelitian didapat 16 (43,2\%) responden yang menilai promotion baik dan tingkat kunjungan baik. Sedangkan ada 17 (45,9\%) responden yang menilai promotion kurang baik dan tingkat kunjungan kurang baik. Hasil uji hipotesis chi square diperoleh p-value sebesar 0,000, kurang dari 0,05, maka dapat disimpulkan bahwa ada hubungan variabel promotion dengan tingkat kunjungan di RS Sahid Sahirman di tahun 2017.

Hasil penelitian ini sejalan dengan penelitian yang dilakukan oleh Wijayanti, dkk ${ }^{18}$ Tahun 2015 yang berjudul "Hubungan Bauran Pemasaran Dengan Loyalitas Pasien Di Unit Rawat Jalan RSUD Kota Makassar" yang menyimpulkan promosi sudah terlaksana dengan baik dan berdampak pada peningkatan jumlah kunjungan pasien.

Lebih lanjut, penelitian ini juga sejalan dengan penelitian Purnamasari, dkk $^{11}$ Tahun 2012 yang berjudul "Hubungan Bauran Pemasaran (Marketing Mix) Dengan Kunjungan Pasien Di Unit Rawat Jalan RSIA Pertiwi Makassar Tahun 2011". Hasil penelitiannya menunjukkan Ada hubungan antara promosi dengan dengan kunjungan pasien di unit rawat jalan Rumah Sakit Ibu dan Anak Pertiwi Makassar. 


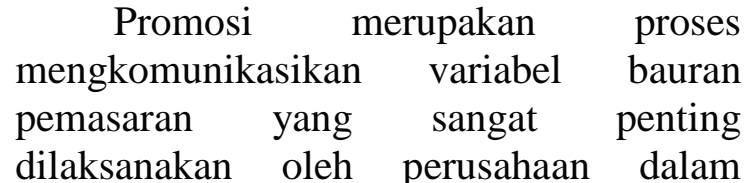
memasarkan produk. Inti dari kegiatan promosi adalah suatu bentuk kegiatan komunikasi pemasaran yang berusaha untuk menyebarkan informasi, mempengaruhi, mengingatkan pasar sasaran agar bersedia menerima, membeli, dan loyal kepada produk yang ditawarkan oleh perusahaan. Menurut peneliti, Rumah Sakit Sahid Sahirman merupakan salah satu bentuk sarana pelayanan kesehatan yang diselenggarakan oleh swasta, saat ini persaingan antar rumah sakit sangat ketat dalam menarik konsumen untuk mengakses pelayanan kesehatan yang ada di rumah sakit tersebut. Salah satu cara yang bisa dilakukan rumah sakit untuk menarik minat konsumen terhadap produknya adalah dengan melakukan kegiatan promosi, saat ini promosi yang dilakukan RS Sahid Sahirman sudah cukup baik, diantaranya telah melaksanakan promosi melalui sosialisasi kesehatan, adanya brosur, leaflet, website, dan kerjasama dengan bidan dan puskesmas dalam hal rujukan pasien.

\section{Hubungan Place Terhadap Tingkat Kunjungan RS Sahid Sahirman}

Berdasarkan hasil penelitian didapat $3(8,1 \%)$ responden yang menilai place kurang baik dan tingkat kunjungan kurang baik. Hasil uji hipotesis chi square diperoleh p-value sebesar 0,001, lebih kecil dari 0,05, maka dapat disimpulkan bahwa ada hubungan variabel place dengan tingkat kunjungan di RS Sahid Sahirman di tahun 2017.

Hasil penelitian ini sejalan dengan hasil penelitian Sholihah dan Susanto Tahun 2015 yang menyatakan bahwa place berpengaruh terhadap minat kunjungan ulang pasien JKN di Poliklinik RSUD Panembahan Senopati. Namun hasil penelitian ini tidak berbeda dengan penelitian yang dilakukan oleh Pondaag, dkk Tahun 2015 yang berjudul
"Pelaksanaan Bauran Pemasaran Dalam Upaya Peningkatan Jumlah Kunjungan Pasien Di RSUD Amurang" yang menyimpulkan faktor-faktor yang mempengaruhi pelaksanaan bauran pemasaran di RSUD Amurang, salah satunya place belum terlaksana dengan baik dan berdampak pada penurunan jumlah kunjungan pasien. $^{20}$

Menurut peneliti, pemilihan lokasi dalam suatu usaha adalah hal utama yang perlu dipertimbangkan. Lokasi strategis menjadi salah satu faktor penting dan sangat menentukan keberhasilan suatu usaha, lokasi usaha berhubungan dengan masalah efisiensi transportasi, sifat bahan baku atau sifat produknya, dan kemudahannya mencapai konsumen. Lokasi juga berpengaruh terhadap kenyamanan pembeli. Lokasi RS Sahid Sahirman saat ini sangat strategis berada di jantung kota Jakarta di Jalan Jenderal Sudirman.

\section{Hubungan People Terhadap Tingkat Kunjungan RS Sahid Sahirman}

Berdasarkan hasil penelitian didapat bahwa 17 (45,9\%) responden yang menilai people baik dan tingkat kunjungan baik, dan 17 (45,9\%) responden menilai people kurang baik dan tingkat kunjungan kurang baik. Hasil uji hipotesis chi square diperoleh p-value sebesar 0,000, kurang dari 0,05, maka dapat disimpulkan bahwa ada hubungan variabel people dengan tingkat kunjungan di RS Sahid Sahirman di tahun 2017.

Hasil penelitian ini sejalan dengan penelitian yang dilakukan oleh Wijayanti, dkk Tahun 2015 yang berjudul "Hubungan Bauran Pemasaran Dengan Loyalitas Pasien Di Unit Rawat Jalan RSUD Kota Makassar" yang menyimpulkan people berdampak pada peningkatan jumlah kunjungan pasien. Sedangkan hasil penelitian ini berbeda dengan hasil penelitian Sholihah dan Susanto (2015) yang menyatakan bahwa people berpengaruh terhadap minat 
kunjungan ulang pasien JKN di Poliklinik RSUD Panembahan Senopati. ${ }^{18}$

Menurut peneliti, dari hasil penelitian faktor sumberdaya manusia di RS Sahid Sahirman sudah sangat baik kualitasnya, hal ini didukung oleh terdapatnya pasien yang menyatakan bahwa perawat/dokter sangat melayani, teliti dan selalu memperhatikan keluhan pasien pada saat melakukan pemeriksaan. Hal ini membuat pasien nyaman sehingga berdampak pada loyalitas pasien tersebut untuk selalu berkunjunga jika ada keluhan sakit.

\section{Hubungan Process Terhadap Tingkat Kunjungan RS Sahid Sahirman}

Berdasarkan hasil penelitian didapat

17 (45,9\%) responden yang menilai process baik dan tingkat kunjungan baik. Sedangkan 20 (54\%) responden yang menilai process kurang baik dan tingkat kunjungan kurang baik. Hasil uji hipotesis chi square diperoleh p-value sebesar 0,000, kurang dari 0,05, maka dapat disimpulkan bahwa ada hubungan variabel process dengan tingkat kunjungan di RS Sahid Sahirman di tahun 2017.

Hasil penelitian ini sejalan dengan penelitian yang dilakukan oleh Wijayanti, dkk Tahun 2015 yang berjudul "Hubungan Bauran Pemasaran Dengan Loyalitas Pasien Di Unit Rawat Jalan RSUD Kota Makassar" yang menyimpulkan people berdampak pada peningkatan jumlah kunjungan pasien. ${ }^{18}$

Hasil penelitian ini sejalan dengan penelitian yang dilakukan Nurhalimmah dan Sugiarsi Tahun 2008 yang berjudul "Gambaran Tingkat Kepuasan Pasien Rawat Jalan Kunjungan Ulang Di Rumah Sakit PKU Muhammadiyah Karanganyar" yang menyatakan mutu jasa Rumah Sakit PKU Muhammadiyah Karanganyar bermutu baik dan berhubungan signifikan dengan kunjungan ulang pasien, mutu termasuk didalamnya adalah process dalam pelayanan di Rumah Sakit. ${ }^{15}$

Process merupakan hal yang penting yang perlu diperhatikan bagi suatu rumah sakit. Proses dapat berpengaruh terhadap loyalitas karena berkaitan dengan bagaimana pelayanan tersebut diberikan kepada pasien, walaupun sebagian besar pendapat pasien baik tetapi masih banyak pasien yang mengeluh tentang lamanya waktu tunggu di rumah sakit. Proses mencakup prosedur pelayanan, termasuk tahap-tahap yang dilalui. Kecepatan dan ketepatan proses dapat dijadikan alat untuk merangsang minat konsumen, seperti prosedur penerimaan pasien yang cepat dan tepat, pelayanan pemeriksaan, pengobatan dan perawatan yang cepat dan tepat, perawat/dokter melakukan jadwal pelayanan dengan tepat, petugas melakukan pelayanan dengan tidak berbelit-belit. Process di Rumah Sakit Sahir Sahirman terbukti baik dan berhubungan erat dengan kunjungan pasien.

\section{Hubungan Physical Evidence Terhadap Tingkat Kunjungan RS Sahid Sahirman}

Berdasarkan hasil penelitian didapat 2 (5,4\%) responden yang menilai physical evidence baik dan tingkat kunjungan baik. Sedangkan 2 (5,4\%) responden yang menilai physical evidence baik dan tingkat kunjungan baik. Hasil uji hipotesis chi square diperoleh p-value sebesar 0,000, kurang dari 0,05, maka dapat disimpulkan bahwa ada hubungan variabel physical evidence dengan tingkat kunjungan di RS Sahid Sahirman di tahun 2017.

Hasil penelitian ini sejalan dengan penelitian sejalan dengan penelitian yang dilakukan oleh Wijayanti, dkk Tahun 2015 yang berjudul "Hubungan Bauran Pemasaran Dengan Loyalitas Pasien Di Unit Rawat Jalan RSUD Kota Makassar" yang menyimpulkan physical evidence berdampak pada peningkatan jumlah kunjungan pasien. ${ }^{18}$

Penelitian ini tidak sejalan dengan hasil penelitian Pondaag, dkk Tahun 2015 yang berjudul "Pelaksanaan Bauran Pemasaran Dalam Upaya Peningkatan Jumlah Kunjungan Pasien Di RSUD Amurang" yang menyimpulkan faktor- 
faktor yang mempengaruhi pelaksanaan bauran pemasaran di RSUD Amurang, salah satunya physical evidence belum terlaksana dengan baik dan berdampak pada penurunan jumlah kunjungan pasien. ${ }^{19}$

Physical evidence merupakan suatu hal yang secara nyata turut mempengaruhi keputusan konsumen untuk membeli dan menggunakan produk jasa yang ditawarkan. Adapun unsur yang termasuk dalam sarana fisik, yaitu lingkungan fisik dalam hal ini bangunan fisik, peralatan, perlengkapan, logo, warna, dan barangbarang lainnya. Seorang pasien dapat langsung menyimpulkan seperti apa rumah sakit saat pertama kali melihat sarana fisik yang terdapat di rumah sakit tersebut. Oleh karena itu, pihak rumah sakit sebaiknya memperhatikan sarana fisik yang terdapat pada rumah sakit agar pasien yang datang merasa nyaman. Berdasarkan hasil penelitian RS Sahid Sahirman telah memiliki physical evidence yang baik.

\section{Kesimpulan}

Dari penelitian ini dapat disimpulkan bahwa terdapat hubungan antara marketing mix dengan tingkat kunjungan RS Sahid Sahirman, hanya price saja yang tidak berhubungan, Oleh karenanya diharapkan Rumah Sakit Sahid Sahirman hendaknya berorientasi pada kualitas layanan untuk dapat bersaing dengan rumah sakit lain. Jika harga (Price) sesuai dengan kualitas layanan maka pasien akan memilih RS Sahid Sahirman yang pada akhirnya terlihat pada tingkat kunjungan yang tinggi.

\section{Saran}

Diharapkan manajemen RS Sahid Sahirman untuk meningkatkan meningkatkan kualitas bauran pemasarannya, dengan memperbaiki kualitas layanan agar sesuai dengan tarif yang dikenakannya, melakukan promosi dengan lebih gencar dengan melalukan kerjasama dengan puskesmas dan klinik disekitarnya. Melakukan pelatihan pada
SDM nya dan terus menerus memperbaiki dan mengembangkan bukti fisik agar tidak ketinggalan dengan perkembangan zaman.

\section{Daftar Pustaka}

1. Undang-Undang Republik Indonesia Nomor 36 Tahun 2009 Kesehatan. Lembaran Negara Republik Indonesia. Jakarta; 2009.

2. Hartono B. Manajemen Pemasaran untuk Rumah Sakit. Jakarta: Rineka Cipta; 2010.

3. Undang-Undang Republik Indonesia Nomor 44 Tahun 2009 Rumah sakit. Lembaran Negara Republik Indonesia. Jakarta; 2009.

4. Dinas Kesehatan Indonesia Tahun 2016. Profil Kesehatan Indonesia; 2016.

5. Kotler P dan Keller. Manajemen Pemasaran. Jilid 1. Edisi ke 13. Jakarta: Erlangga; 2009.

6. Firdaus M. Manajemen Agribisnis. Jakarta: PT Bumi Aksara; 2010.

7. Kotler P. Manajemen Pemasaran. Edisi Milenium. Jakarta: PT Indeks Kelompok Gramedia. 2000.

8. Zeithaml VA dan Bitner MJ. Service Marketing integrating Cutomer Focus Across The Firm. Second Edition Hill. New York: McGraw; 2000.

9. Selang. Bauran Pemasaran (Marketing Mix) Pengaruhnya Terhadap Loyalitas Konsumen Fres Mart Bahu Mall Manado. Jurnal EMBA. Manado: Universitas Sam Ratulangi; 2013.

10. Augusty F. Metode Penelitian Manajemen: Pedoman Penelitian untuk Penulisan Skripsi, Tesis dan disertai Ilmu Manajemen. Semarang: Badan Penerbit Universitas Diponegoro; 2013.

11. Purnamasari AH. Nurhayani, Asiah $H$ dan Yusran A. Hubungan Bauran Pemasaran (Marketing Mix) Dengan Kunjungan Pasien Di Unit Rawat Jalan RSIA Pertiwi Makassar ; 2011.

12. Kotler P. Manajemen Pemasaran. Edisi Millenium. Jakarta: PT Prenhallindo; 2008.

13. Profil RS Sahid Sahrman Tahun 2017. https://www.ssmh.co.id/. Diakses pada tanggal 17 Desember 2017.

14. Hastono, S. Analisa Data Kesehatan. Jakarta: Universitas Indonesia; 2007.

15. Nurhalimmah F dan Sugiarsi S. Gambaran Tingkat Kepuasan Pasien Rawat Jalan Kunjungan Ulang Di Rumah Sakit Pku Muhammadiyah Karanganyar. Jurnal Kesehatan; 2008.

16. Retnaningtyas, Woro SE dan Mafrurrochim $\mathrm{H}$. Persepsi Pasien terhadap Bauran Pemasaran Rumah Sakit dan Pilihan Rumah Sakit. Jurnal Kedokteran Brawijaya; 2016.

17. Rifai MI dan Susanto. Pengaruh Kualitas Pelayanan dan Bauran Pemasaran terhadap Kepuasan Pasien Rumah Sakit. Jurnal Kesehatan Masyarakat; 2016. 
18. Wijayanti SD, Amir MY dan Indar. Hubungan Bauran Pemasaran Dengan Loyalitas Pasien Di Unit Rawat Jalan RSUD Kota Makassar. Jurnal Online; 2015.

19. Pondaag C dan Massie K. Pelaksanaan Bauran Pemasaran Dalam Upaya Peningkatan Jumlah Kunjungan Pasien Di RSUD Amurang. Jurnal Online; 2015.
20. Mar'atush SA dan Susanto. Pengaruh Bauran Pemasaran (Marketing Mix) Terhadap Minat Kunjungan Ulang Pasien Jaminan Kesehatan Nasional (JKN) Di Unit Rawat Jalan Rsud Panembahan Senopati Bantul. Jurnal Online; 2015. 